Original Article

\title{
A STUDY TO ASSESS THE CONTRAST SENSITIVITY OF THE HUMAN VISUAL SYSTEM IN PATIENTS WITH OR WITHOUT DIABETES IN A TERTIARY CARE HOSPITAL
}

\author{
NIKITA RAJGADIA, BINDU BHASKARAN*, N. DIVYA, V. PANIMALAR A. VEERAMANI, SYEDA SADIYA IKRAM \\ Department of Ophthalmology, Saveetha Medical College, Chennai, Tamil Nadu \\ Email: drbidubhas@gmail.com
}

Received: 10 Jul 2020, Revised and Accepted: 08 Sep 2020

\section{ABSTRACT}

Objective: The objective of our study was to assess the variations in contrast sensitivity values of normoglycemic subjects and that of type II diabetic subjects of the same age group. It was also aimed at finding the visual acuities and study the associations of it with contrast sensitivity if any.

Methods: It was a hospital-based comparative cross-sectional descriptive study conducted in the out-patient department of the Department of Ophthalmology, Saveetha Medical College, Hospital, Chennai. Visual Acuity and Contrast Sensitivity of 50 Type II Diabetic individuals and 50 ageequivalent control group subjects were measured using the Snellen's chart and Pelli-Robson chart, respectively, during the months of January to March 2020.

Results: Contrast Sensitivity measurements from 50 subjects with Non-Insulin dependent Diabetes Mellitus (NIDDM) were obtained. The subjects were the ones who had minimal or no diabetic retinopathy. It was observed that there is a significant association between reduced contrast sensitivity and Diabetes (P value<.00008). We also noted that CS may be reduced without corresponding loss of Visual Acuity. Hence, both visual acuity and contrast sensitivity measurements are helpful in the assessment of visual impairment due to diabetic eye disease.

Conclusion: The contrast sensitivity can be seen as an early marker for visual impairment in diabetic eye care.

Keywords: Visual acuity, Pelli-Robson Chart, Diabetic Eye diseases

(C) 2020 The Authors. Published by Innovare Academic Sciences Pvt Ltd. This is an open access article under the CC BY license (http://creativecommons.org/licenses/by/4.0/) DOI: http://dx.doi.org/10.22159/ijcpr.2020v12i6.40274. Journal homepage: https://innovareacademics.in/journals/index.php/ijcpr

\section{INTRODUCTION}

Diabetes is a chronic, metabolic disease resulting from inability of pancreas to produce insulin or resistance of organs to Insulin [1]. Uncontrolled and long-standing diabetes results into hyperglycemia, which causes damage to various organs. In eye, high blood glucose can lead to complications like diabetic eye disease, which includes diabetic retinopathy, diabetic macular edema, cataracts and glaucoma. Diabetic Retinopathy is a common consequence of Diabetes and is among the major causes of preventable blindness in India [2], emerging as the diabetic capital of the world now [3].

According to 2019 WHO study, Globally, approx 422 million people suffer from diabetes, the majority living in low-and middle-income countries, and 1.6 million deaths are directly attributed to diabetes each year [1]. Nationwide, roughly 72.96 million adults are Diabetic. As per Indian Heart Association, In India 109 Million people would have Diabetes by the end of the year 2035 [4]. The prevalence of Diabetic Retinopathy in urban population was found to be $18 \%$ [3].

It is, therefore, important that diabetic individuals be examined routinely so as to prevent disease from progressing to advanced stages and prevention of diabetic eye diseases. While fundus examination is done to clinically detect microvascular changes, functional tests may be used as early indicators of disease progression [3]. Components of Visual function include Visual Acuity, Dark adaptation, Contrast sensitivity (CS) etc.

Visual acuity is suggestive of how well a person sees using the Snellen's Chart. If the patient reads 6/6, we say that the acuities are normal. But it may be hard for him to distinguish an object from its surrounding even with normal visual acuities [5]. Such a patient might have problems with night driving or may require more light to read [6]. This measure of differentiating the luminance of an object from the luminance of the surrounding area is referred to as Contrast Sensitivity and Contrast threshold is the point at which the object becomes indistinguishable from its surrounding [5]. PelliRobson Chart is one such chart of same-sized letters with reducing contrast, where the letters are written in black on a white background [6]. The chart consists of 6 letters in each row arranged into two triplets of different contrast. Contrast sensitivity threshold of an individual can be marked by making a person read this chart.

Its values are low in patients with Glaucoma, Diabetic Eye diseases and Cataracts etc [6]. Our study was done to establish that NonInsulin Dependent Diabetes Mellitus (NIDDM) affects the contrast sensitivity values.

\section{MATERIALS AND METHODS}

Our study was duly approved by the Institutional Ethics Committee (IEC).

\section{Study design and duration}

It was a hospital-based comparative, cross-sectional, descriptive study conducted between the months of January and March 2020 in the Department of Ophthalmology, Saveetha Medical College, Chennai, across the Diabetic population and the age-equivalent nondiabetic control subjects of Chennai, Tamil Nadu.

\section{Inclusion criteria}

The individuals who were willing to participate in our study and give consent belonging to the following categories were included in the study.

- Patients above $40 \mathrm{y}$ of age.

- Type II Diabetic subjects with or without Retinopathy.

- Age equivalent nondiabetic control subjects.

Exclusion criteria

- Subjects below the age of $40 \mathrm{y}$

- Type 1 Diabetes Subjects

- Patients who were unwilling to participate. 


\section{Study procedure}

Once the Institutional Ethics Committee gave permission, we selected Diabetic subjects based on fasting and post-prandial blood glucose values. Individuals with FBG $>126 \mathrm{mg} / \mathrm{dl}, \mathrm{PP}>200 \mathrm{mg} / \mathrm{dl}$ and HbA1c $>6.5 \%$ were taken as diabetic [7]. The visual acuity was checked using the Snellens Chart. For Contrast Sensitivity, the PelliRobson Chart was used, which is a definitive measurement of low spatial frequency CS $(0.5-2$ cycles). The patients were made to sit at a 3 metre distance from the Pelli-Robson chart, and were asked to read the letters, by occluding the right eye, followed by the left eye. If he/she could not respond, we waited for few seconds for them to try again and guess the alphabet. The test score was recorded by the faintest triplet, of which atleast two letters are read correctly. The three letters have the same contrast hence allowing the patient three trials for each contrast [8]. The log CS value for this triplet is provided by the number which is nearest to the triplet on the scoring pad, either on the left or right side.

The demographic details, history related to diabetes, and the resultant CS score (in log units), along with their blood glucose values were noted. The same procedure was done to record the values of nondiabetic control group and values noted. The resultant values of each groups were then compared, and a hypothesis was formulated. For the analysis of data, Chi square test was done.

\section{RESULTS}

This study comprised of 50 Diabetic and 50 Non-Diabetic subjects. Chart 1 shows the sex distribution of both groups of our sample population. The age distribution of each group of individuals is illustrated in chart 2 .

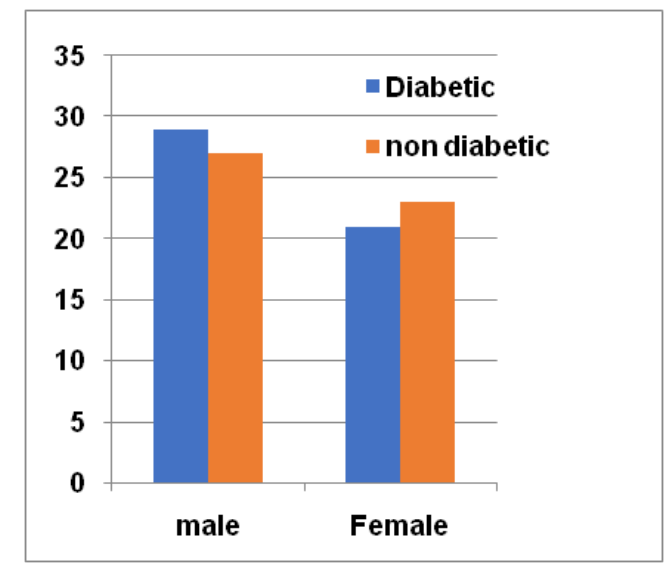

Chart 1

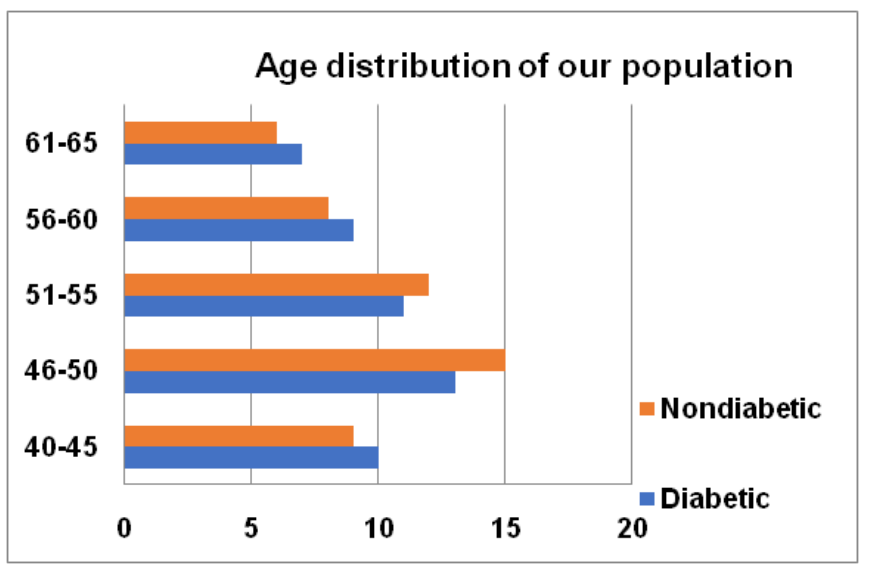

Chart 2
The Contrast Sensitivity values were classified into the following three categories and based on that, the results were interpreted.

CS $<1$ : Visual Disability

$\mathrm{CS}<1.5$ : Visual Impairment
$\mathrm{CS} \geq 2$ : Normal

Data was summarized using means, standard deviation and tables. To study the relationship of two variables, chi-square test was used. Values of $\mathrm{P}<.05$ was considered to be significant.

Table 1: Biochemical parameters in both diabetic and non-diabetic patients

\begin{tabular}{lll}
\hline Parameters & Non-diabetics & Diabetics \\
\hline Fasting blood glucose & $90.76 \pm 10.85$ & $145 \pm 31.39$ \\
Post Prandial blood glucose & $112 \pm 11.58$ & $200 \pm 16.54$ \\
HbA1c & $5.25 \pm 0.17$ & $8.52 \pm 0.52$ \\
\hline
\end{tabular}

The sample size, the mean and standard deviation of each group are listed in table 2

Table 2: Contrast sensitivity levels

\begin{tabular}{llll}
\hline Group & N & Mean & Standard deviation \\
\hline Diabetic & 50 & 1.1045 & 0.623087 \\
Non diabetic & 50 & 1.5930 & 0.548836 \\
\hline
\end{tabular}

Table 3: Contrast sensitivity scores of each group

\begin{tabular}{lllll}
\hline Groups & Visual disability & Visual impairment & Normal & Total \\
\hline Diabetic & 23 & 17 & 10 & 50 \\
Non diabetic & 9 & 10 & 31 & 50 \\
Total & 32 & 27 & 41 & 100 \\
\hline
\end{tabular}

Assuming The Null hypothesis holds true here, which states that there is no significant association between Diabetes Mellitus and reduction in CS, chi-square value was calculated. The resultant value can be cited as:

$\mathrm{X}^{2}(2, \mathrm{~N}=100)=18.69, \mathrm{p}<.00008$
Since the ${ }^{*} \mathrm{P}$ value $<0.05$, The Null Hypothesis is rejected. And it implies that there is a significant relationship between Diabetes Mellitus and loss of Contrast sensitivity.

It was also observed that even the patients whose visual acuity were normal had reduced CS, indicating the importance of measuring both 
the quantities. Furthermore, we noticed that there was no association between $\mathrm{CS}$ and sex of the sample population. ( ${ }^{* *} \mathrm{P}$ value $<.6870$ ). The association of CS with increasing age was also found to be insignificant ( ${ }^{* * *} \mathrm{P}$ value $\left.<.36922\right)$.

It was observed that most of the disabled subjects were the ones whose blood glucose values were very high and three-month diabetic control was poor (HbA1c>8).

\section{DISCUSSION}

Diabetes Mellitus is a chronic, metabolic disease which, if uncontrolled, leads to diabetic eye diseases. It makes an individual more susceptible to Vision defects or even blindness [9]. Our focus was on reduced Contrast Sensitivity in Diabetic patients. CS is the minimum difference in intensity that a person can resolve between an object and its background [10]. The effect of Diabetes Mellitus (Type II) on loss of Contrast Sensitivity was studied on 50 diabetic subjects and 50 age-equivalent non diabetic subjects. The Pelli-Robson chart is an easy, quick and cheap method of measuring the spatial Contrast Sensitivity [3]. Hence, we chose this method to categorize subjects as having Visual disability $(\mathrm{CS}<0.5)$, Visual impairment $(\mathrm{CS}<1.5)$ or Normal Contrast $(\geq 2.0)$.

On analysing the quantities statistically, we found a P value $<.0008$, proving that diabetes leads to loss of contrast in otherwise healthy individuals. Furthermore, It was noted that the subjects whose Visual acuities were normal, also had difficulties in detecting Contrast [11]. Thus, the Pelli-Robson chart is more sensitive for recognizing visual defects than Snellens chart [12] According to a previous study, CS is known to decrease with advancing age [13]. However, we did not find any significant association between age groups and CS values ( ${ }^{* * *} \mathrm{P}$ value<.36922). The outcomes may differ due to the heterogeneity in the sociodemographic characteristics of the study population. There exists no association in the sex of the patient and reduced CS [14]. From previous studies and in our study, it was observed that the subjects with uncontrolled hyperglycemia were more prone to losing contrast [15]. On the other hand, those whose values were in control (HbA1c $\leq 7)$ showed better contrast even at advanced ages.

\section{CONCLUSION}

For the management of Diabetic eye diseases, along with Visual Acuity, Contrast Sensitivity should be checked routinely as patients showing normal Visual Acuity might also have a reduced CS. Moreover, CS has been known to reduce long before patients develop clinically-evident retinopathy and hence be used as a useful index to prevent complications and retinal changes [16].

\section{ACKNOWLEDGEMENT}

The necessary facilities for this work was provided and supported by Saveetha Medical College Hospital, Chennai.

\section{FUNDING}

Nil

\section{AUTHORS CONTRIBUTIONS}

All the authors have contributed equally.

\section{CONFLICT OF INTERESTS}

Declared none

\section{REFERENCES}

1. World Health Organization. Global report on diabetes: executive summary (No. WHO/NMH/NVI/16.3). World Health Organization; 2016.

2. Klein BE. Overview of epidemiologic studies of diabetic retinopathy. Ophthalmic Epidemiol 2007;14:179-83.

3. Noticewala V, Shastri M. A study of contrast sensitivity changes in normal individual and diabetic patients with and without diabetic retinopathy. Int J Res Med Sci 2017;5:4840-5.

4. "Overview" Indian Heart Association; 2020.

5. Aoa.org. Available from: https://www.aoa.org/Documents/ optometric-staff/Articles/Contrast-Sensitivity.pdf [Last accessed on 18 Aug 2020]

6. Slideshare.net. Contrast Sensitivity; 2020. Available from: https://www.slideshare.net/laxmieyeinstitute/contrastsensitivity [Last accessed on 18 Aug 2020]

7. Mellitus D. Diagnosis and classification of diabetes mellitus. Diabetes Care 2005;28:S5-S10.

8. Parede Tais, Torricelli Andre, Mukai Adriana, Netto Marcelo, Bechara Samir. Quality of vision in refractive and cataract surgery, indirect measurers: review article. Arquivos brasileiros de oftalmologia. 2013;76:386-90.

9. Davidson JA, Ciulla TA, McGill JB, Kles KA, Anderson PW. How the diabetic eye loses vision. Endocrine 2007;32:107-16.

10. Sciencedirect.com. Contrast sensitivity-an overview | Sciencedirect topics. Available from: https://www.sciencedirect.com/topics/medicine-anddentistry/contrast-

sensitivity\#: :text=Visual\%20contrast $\% 20$ sensitivity $\% 20$ is $\%$ 20a,41.1). [Last accessed on 18 Aug 2020]

11. National Research Council (US) Committee on Disability Determination for Individuals with Visual Impairments; Lennie P, Van Hemel SB. editors. Visual Impairments: Determining Eligibility for Social Security Benefits. Washington (DC): National Academies Press (US); 2002. 2, TESTS OF VISUAL FUNCTIONS. Available from: https://www.ncbi.nlm.nih.gov/

12. books/NBK207559/ [Last accessed on 18 Aug 2020]

13. Wender M. Value of pelli-robson contrast sensitivity chart for evaluation of visual system in multiple sclerosis patients. Neurologia I Neurochirurgia Polska 2006;41:141.

14. Sieiro RDO, Coelho LM, Boas PCV, Fonseca SC, Souza SR, Guimaraes TDP. Avaliacao da funcao de sensibilidade ao contraste em diferentes faixas etarias nas medias e altas frequencias espaciais. Revista Brasileira de Oftalmologia 2016;75:296-9.

15. Darius S, Bergmann L, Blaschke S, Bockelmann I. Influence of sex and age on contrast sensitivity subject to the applied method. Klinische Monatsblatter Fur Augenheilkunde 2018;235:212-8.

16. Mangouritsas G, Katoulis E, Kepaptsoglou O, Zoupas C. Effekt von provozierter Hyperglykamie auf die Kontrastempfindlichkeitsfunktion bei insulinpflichtigen Diabetikern [Effect of induced hyperglycemia on contrast sensitivity function in insulin-dependent diabetic patients]. Ophthalmologe 1995;92:142-7.

17. Sokol S, Moskowitz A, Skarf B, Evans R, Molitch M, Senior B. Contrast sensitivity in diabetics with and without background retinopathy. Arch Ophthalmol 1985;103:51-4. 